\title{
A case study on using the FDS tool for on-site fire investigation
}

\author{
Ligia Ioana Tuhuț*, Vlad Mihai Pasculescu, Nicolae Ioan Vlasin, and Florin Manea \\ National Institute for Research and Development in Mine Safety and Protection to Explosion - \\ INSEMEX Petroşani, 32-34 G-ral Vasile Milea St., 332047 - Petroşani, Hunedoara County, Romania
}

\begin{abstract}
When investigating a fire type event, one has to have in mind that maybe the most important aspect is the identification of the source of ignition. Nowadays, commercial and open-source software are available and can be used during such investigations. The fire field model - Fire Dynamics Simulator (FDS) is one of the most popular numerical model used for fire investigation. The purpose of this paper is to demonstrate the importance of computer simulations when two hypotheses, Arson effect with multiple fireplaces and electric short circuit are taken into consideration as the cause of the fire. To virtually simulate the findings at the fire site, the FDS tool (Computational Fluid Dynamics) was used. Computational simulations for the two scenarios revealed that the multiple fireplaces scenario, the initial ignition at both the warehouse and the roof of the annex, illustrates the effects of the fire in a similar way to those found at the site, while the scenario with the initial source on the wall of the room with the electrical panel produces a fire located at the level of the construction and is not transmitted to the annex. Consequently, the results obtained validate the multiple outbreak (Arson effect) scenario.
\end{abstract}

\section{Introduction}

Fires have been one of the most destructive events that mankind has dealt with. Whether it's forest fires, building fires or electrical fires, they can be classified in five different ways depending on the agent that fuels them: Class A, Class B, Class C, Class D, and Class K. Each type of fire involves different flammable materials such as gases, metals, oils, petrol etc and requires a special approach.

Given the fact that fire events are so recurring and its casualties are so devastating, a lot of research and resources have been invested in analysing and studying the fire effects, its spreading and especially its cause. Knowing the cause, the source of ignition, can help in preventing these types of events to occur.

After the fire has been extinguished, how do we know if we are dealing with a spontaneous fire or something much eviller is at stake? Because of the highly technological breakthroughs, intelligent computers and a lot of research, we can now identify the source of a fire event with the help of computer simulations, this being the purpose of this article. A

\footnotetext{
*Corresponding author: ligia.tuhut@insemex.ro
} 
situation was given, with a fire event that produced devastating property damage. The obvious question was risen: was the fire spontaneous due to an electric short-circuit or are we dealing with an arsonist? Using Fire Dynamics Simulator (FDS), the two scenarios were virtually simulated and the results were conclusive enough to validate one of the scenarios as being the cause of the fire.

FDS (Fire Dynamics Simulator) is an important tool for simulating fire spread processes and its accuracy has been tested in various scenarios such as in a cable tunnel fire, building fires, travelling fires through a compartment. [1]

\section{Fire dynamics simulator (FDS)}

Fire virtual simulations aims to estimate the temperatures occurring in proximity of the igniting source, the ignition possibility, following the alleged source, the combustible materials and spreading the flame front to the proximate vicinity, where were combustible materials with a significant contribution in fire propagation.

Fire Dynamics Simulator (FDS) is a computational fluid dynamics (CFD) model of firedriven fluid flow. The software solves numerically a form of the Navier-Stokes equations appropriate for low-speed, thermally-driven flow, with an emphasis on smoke and heat transport from fires. FDS can reduce the number of expensive full-scale tests needed from testing laboratories by simulating these experiments, facilitating product designs with a greater chance of passing full-scale tests earlier in the testing series.

Considered by the program developers, but also by other researchers in the field, the validation of FDS can be divided into:

- Comparison with tests performed on a real scale, in order to evaluate the FDS code;

- Comparison with engineering correlations;

- Comparison with the results of scale tests;

- Comparison with standard test;

- Comparison through documented experience in the field of fires.

This software has been used in a wide-range area of expertise, such as its capabilities for predicting upward flame spread [2], its accuracy to establish cable tunnel model, set materials, such as fire sprinkler water parameters [3], or to confirm a fire development process and to analyze the main cause of death, this showing that numerical reconstruction methods can simulate the fire accidents effectively. [4]

In our particular case, FDS proved to be an excellent tool in validating one of the fire scenarios that was taken into consideration based on what was found at the fire site.

\section{Case study}

\subsection{Hypothesis no. 1. Fire source of electrical initiation (short circuit in the electrical panel)}

In this case study, we had two hypotheses:

- Hypothesis no. 1. Fire source of electrical initiation (short circuit in the electrical panel)

- Hypothesis no. 2. Arson effect - intentional action of the ignition source (multiple fireplaces)

In the modeled scenarios, the presumed ignition source initiates the combustion process of nearby combustible materials in an interval that represents the sum between the pyrolysis time of the solid and the induction time of the gas phase. 
At the fire site, there was found these following damages [4]:

- Partial destruction of the roof of the house, destruction of the summer kitchen, the total destruction of two warehouse, destruction of the wood storage annex, the total destruction of the garage, partial destruction of the animal annex.

Following this, the geometry of the structures was built and the two scenarios were modeled using the FDS tool.

To perform computational fire simulations, the geometry of the entire residential complex of the building was built as shown in Fig. 3.1

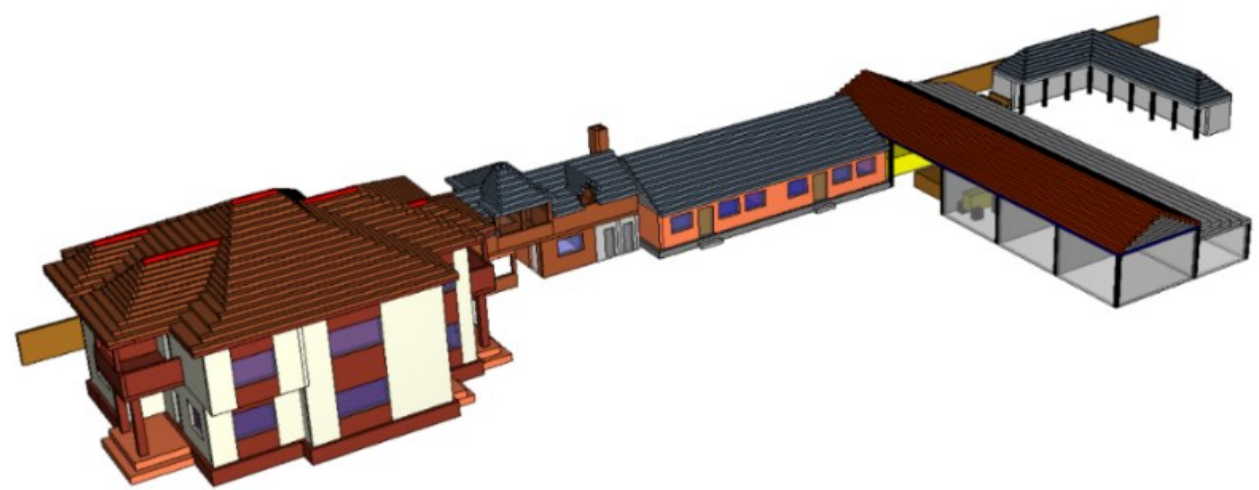

Fig. 3.1 Geometry of the entire residential complex of the building

This hypothesis (short circuit in the electrical panel), is supported by a series of arguments able to explain the initiation of the fire starting from the electricity distribution board: the presence of uncalibrated fusible electrical fuses, the age of the electrical system, with conductors placed on the wall surface, unprotected, traces beading of electrical conductors, probably as a result of a short electrical circuit simulated in Fig. 3.2.

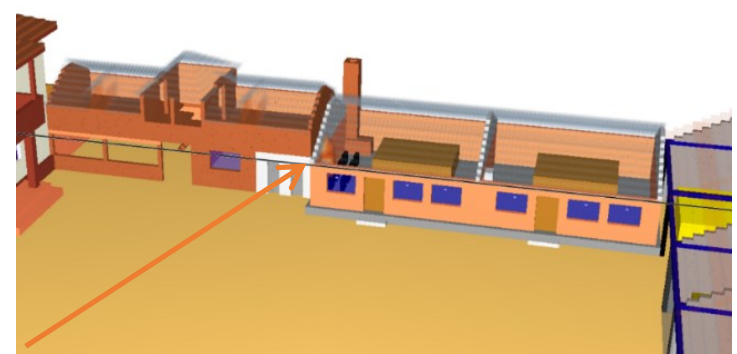

Fig. 3.2 Fire source of electrical initiation (hypothesis 1)

The following sequence of images shows the spread of the fire (Fig. 3.3), starting from the electrical panel, the development of the flame having as support the insulation of electrical cables laid on the wall, above the distribution panel, burning the wooden structure of the roof then the evolution of the fire towards the connected buildings: the summer kitchen and the feed store, respectively garages, as shown in Fig. 3.4 a-e. 

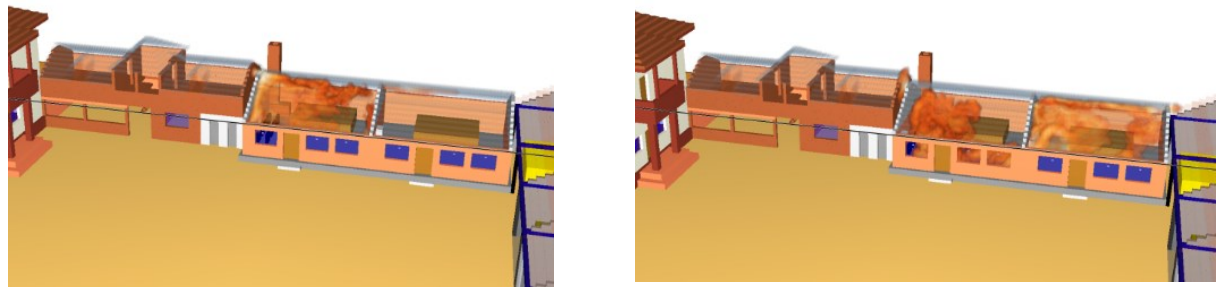

Fig. 3.3 The fire spread through the interior of the attic, to the adjoining room, and then to the adjacent buildings

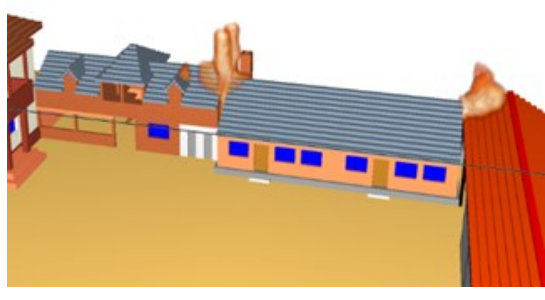

a)

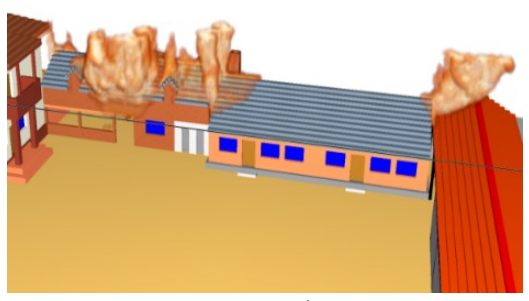

c)

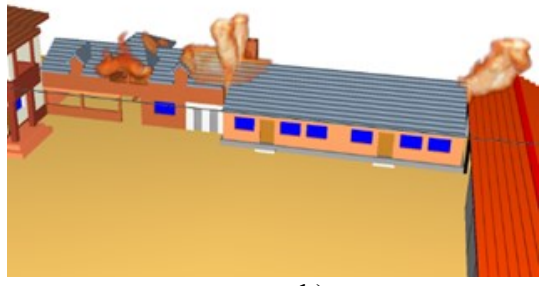

b)

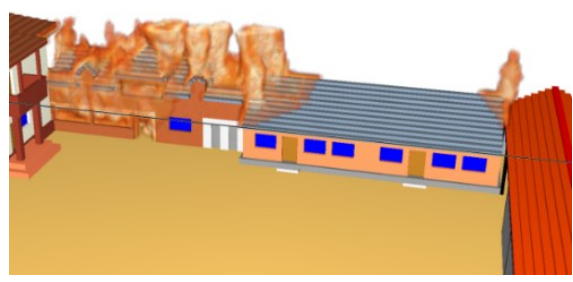

d)

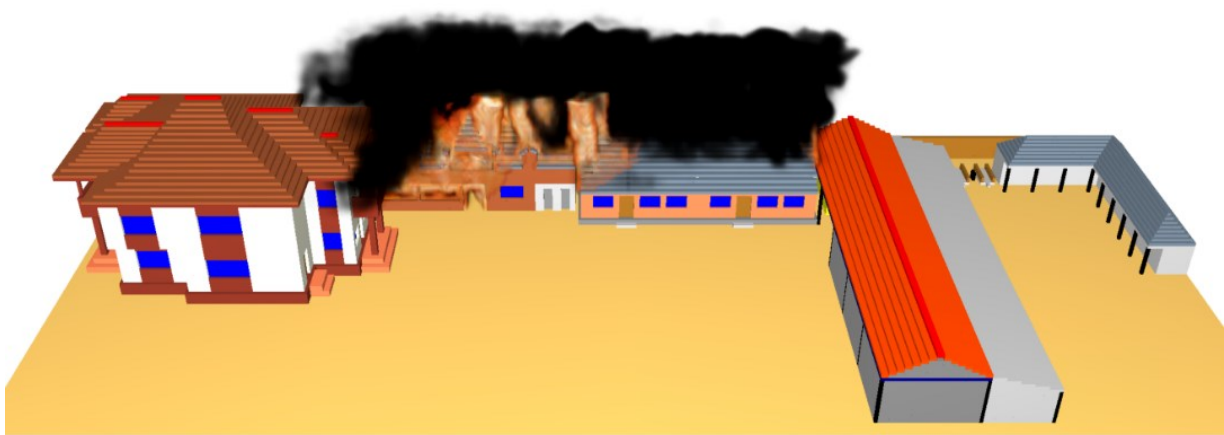

e)

Fig. 3.4 Fire spreading at the level of the attic and the floor of the summer kitchen, also spreading to the residential building's deck 
The combustible materials used in the virtual model of the enclosures are the ones found by the fire brigades at the fire site, respectively:

- wood material

- rubber

- plastics

The physical and thermal characteristics of some materials presumed to be involved in the fire are included in Table no. 1.

Following the computer simulations, it can be seen that the scenario with the initial source on the wall of the room with the electrical panel produces a fire located in the residential complex (wooden kitchen, workshop, garages, wood storage) and is not transmitted to the animal annex. Because of this, we can classify this hypothesis as unlikely.

Table 1. Material characteristics

\begin{tabular}{|l|c|c|c|c|c|c}
\hline $\begin{array}{c}\text { Material/ } \\
\text { Substance }\end{array}$ & $\begin{array}{c}\text { Density } \\
{\left[\mathbf{k g} / \mathbf{m}^{3}\right]}\end{array}$ & $\begin{array}{c}\text { Specific heat } \\
{[\mathbf{k J} /(\mathbf{k g} \cdot \mathbf{K}]}\end{array}$ & $\begin{array}{c}\text { Thermal } \\
\text { conductivity } \\
{[\mathbf{W} /(\mathbf{m} \cdot \mathbf{K})]}\end{array}$ & $\begin{array}{c}\text { Heat } \\
\text { release } \\
{[\mathbf{k J} / \mathbf{k g}]}\end{array}$ & $\begin{array}{c}\text { Heat release } \\
\text { per unit area } \\
{\left[\mathbf{k W} / \mathbf{m}^{2}\right]}\end{array}$ & $\begin{array}{c}\text { Ignition } \\
\text { temperatur } \\
{\left[{ }^{\circ} \mathbf{C}\right]}\end{array}$ \\
\hline Wood & 640 & 2,85 & 0,14 & 17000 & 200 & 240 \\
\hline OSB & 660 & 1,70 & 0,126 & 13400 & 100 & 280 \\
\hline Paper & 790 & 1,336 & 0,05 & 18400 & 170 & $218-246$ \\
\hline Textiles & 240 & 1,357 & 0,1 & 17000 & 250 & 220 \\
\hline & & $1,29\left(23^{\circ} \mathrm{C}\right)$ & $0,192\left(23^{\circ} \mathrm{C}\right)$ & & & \\
PVC & 1380 & $\begin{array}{c}1,35\left(50^{\circ} \mathrm{C}\right) \\
1,47\left(100^{\circ} \mathrm{C}\right)\end{array}$ & $\begin{array}{c}0,175\left(50^{\circ} \mathrm{C}\right) \\
0,147\left(100^{\circ} \mathrm{C}\right)\end{array}$ & 20000 & 312 & 390 \\
& & $1,59\left(150^{\circ} \mathrm{C}\right)$ & $0,134\left(150^{\circ} \mathrm{C}\right)$ & & & \\
\hline Plastic & 950 & 1,67 & 0,18 & 31000 & 400 & 349 \\
\hline
\end{tabular}

\subsection{Hypothesis no. 2. Arson effect - intentional action of the ignition source (multiple fireplaces)}

Arson is a crime of wilfully and maliciously setting fire to or property. The crime is typically classified as a felony, with instances involving a greater degree of risk to human life or property carrying a stricter penalty.

For this hypothesis, the presence of two ignition sources (multiple fireplaces) was taken into account, as a result of the use of ignition supplies (lighter / matches) or combustible substances that led to the deliberate burning of the barn covered with tin and OSB walls, respectively of the roof of the animal shelter.

The main combustible material used by arsonists is flammable liquids, usually derived both as initial fuel and as an accelerator. In the first case, a fire-starting point, often encountered by experienced arsonists, is a fuel wall. Following the ascending direction on the construction element, the fire reaches under the ceiling, where the maximum propagation and intensification of the combustion takes place. In the second case, the flammable liquid is used as an accelerator for the combustion of solid materials (usually textiles - cloths, waste or paper).

In this case, the fire starts from several outbreaks, located according to Figure 3.5 shown below, and evolves rapidly to the annex (Fig. 3.6. and 3.7), due to the highly flammable properties and the amount of material stored. The fire spreads and reaches the warehouse as shown in Fig. 3.8 transforming into a general burning at the level of the former workshop and storage spaces as in Fig. 3.9. The total damage of the fire can be seen in Fig. 3.10. 


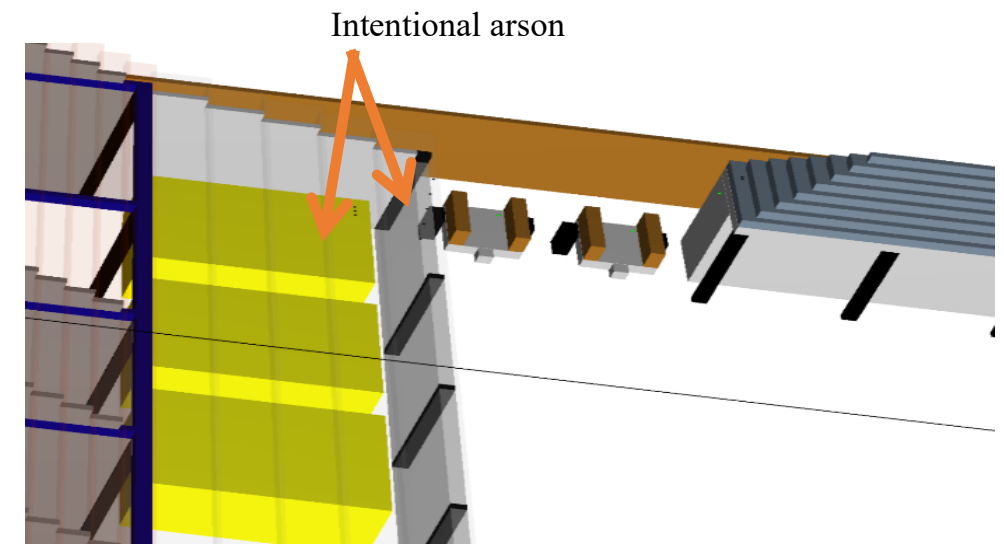

Fig. 3.5 Multiple outbreaks due to deliberate burning of combustible walls

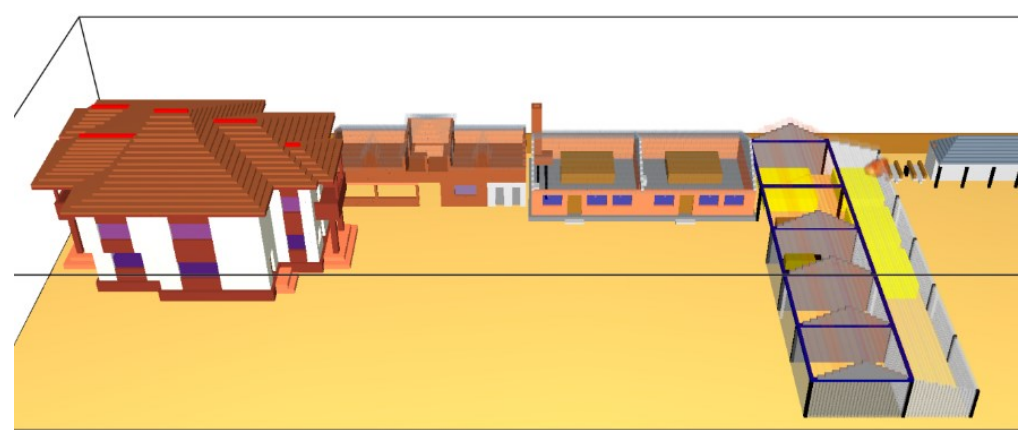

Fig. 3.6 Lighting of the wooden wall of the annex

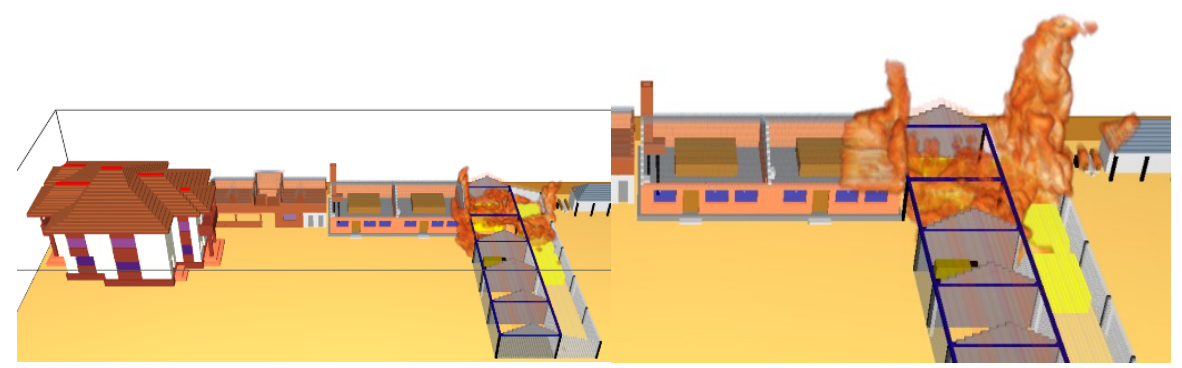

Fig. 3.7 Generalization of the fire throughout the annex

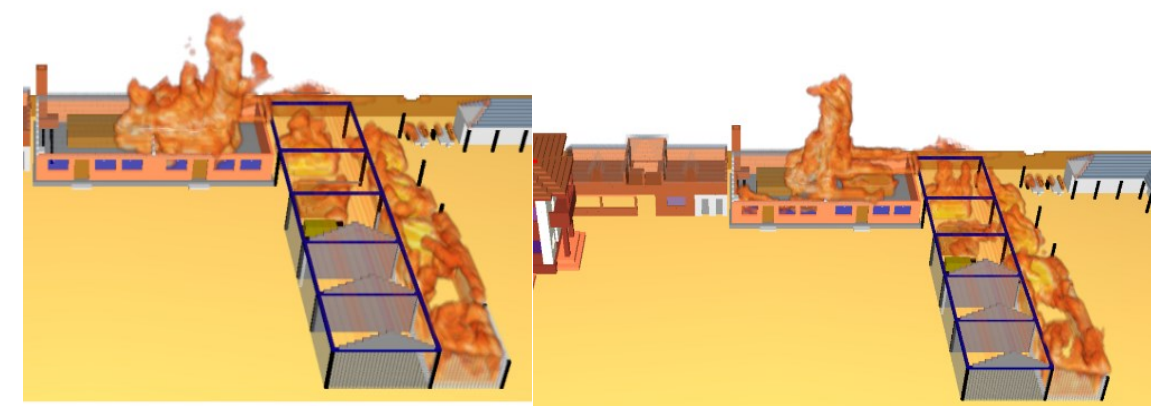

Fig. 3.8 The evolution of the fire towards the first warehouse (towards the summer kitchen) 


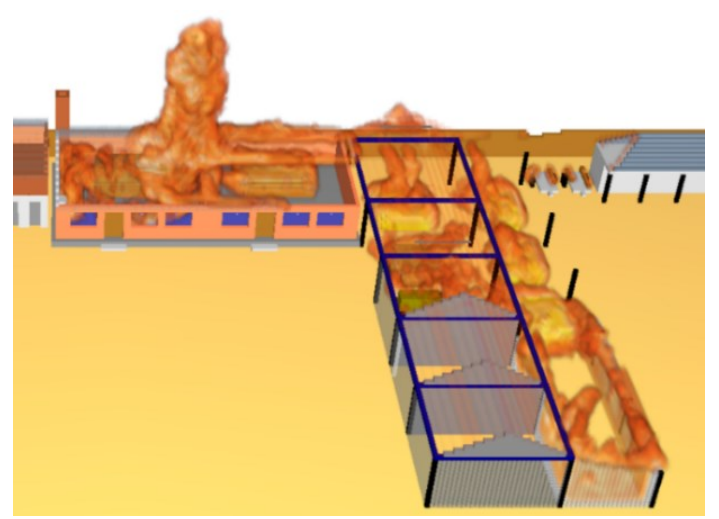

Fig. 3.9 Generalized burning at the level of the former workshop and storage spaces

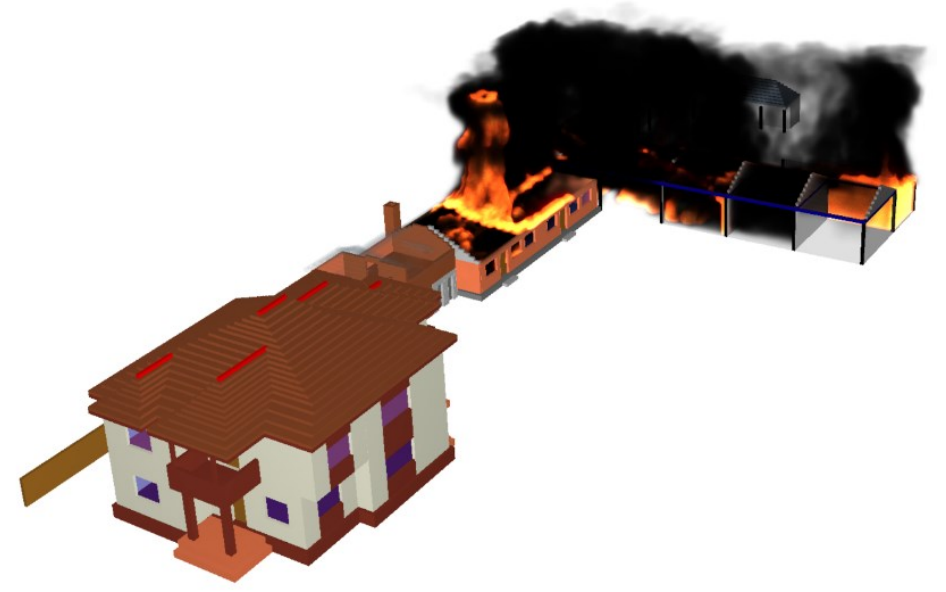

Fig. 3.10 The degree of damage to the set of buildings, at the end of the simulation of the second hypothesis.

\section{Conclusions}

Computer simulations for the two scenarios revealed that the multiple fireplaces scenario (arson effect), the initial ignition both at the workshop and at the roof of the animal annex, illustrates the effects of the fire in a similar way to those found at the fire site, while the scenario with the original source on the wall of the room with the electrical panel (shortcircuit) produces a fire located at the level of the building assembly and is not transmitted to the animal annex. Consequently, the results obtained validate the multiple-focus scenario.

The aim of the paper was to illustrate the benefits of using the FDS Software during a technical expertise investigation. By comparing the probes and materials found on site with the FDS simulations, one can agree that the correct using of the tool reduces the amount of time spent on the investigation and also significantly reduces the theories number of the fire causes.

FDS Software is considered one of the most accurate virtual simulation and computing software in the world. FDS was selected as a model for the World Trade Center disaster investigation. The results of comparing FDS predictions with experimental measurements were considered close enough to warrant the use of FDS as a thermal simulator in the compartments analyzed as part of the World Trade Center investigation. 


\section{References}

1. B. Zhou, YP. Xu, T. Zhang, SIMULTECH2011, FDS Simulation of Cable- Tunnel-Fire-Fighting Water Spray Test-Comparison of Model Results with Experimental Data (Nanjing, China, 2008

2. JW. Kwon, NA. Dembsey, CW Lautanberger, Fire Technol. 43, 255-284 (2007)

3. Y. Liu, SZ. Xu, L. Yan, ICICTA, Study on Hotel Fire Investigation Based on FDS (Changsha, China, 2014)

4. M. C. Suvar, N. I. Vlasin, V. M. Pasculescu, E. Ghicioi, SGEM 2016, Analysis of the impact of using High Performance Computing in fire modeling (Albena, Bulgaria, 2016) 